\title{
Age Related Metabolic Syndrome Among Hemodialysis Patients in Gorgan, Iran
}

\author{
Abdoljalal Marjani $^{*}, 1$, Mohammad Moujerloo ${ }^{2}$ and Sharabeh Hezarkhani ${ }^{2}$
}

${ }^{I}$ Department of Biochemistry and Biophysics, Metabolic Disorders Research Center, Gorgan Faculty of Medicine, Golestan University of Medical Sciences, Gorgan, Iran

${ }^{2}$ Department of Internal Medicine, Gorgan Faculty of Medicine, Golestan University of Medical Sciences, Gorgan, Iran

\begin{abstract}
People with metabolic syndrome are at high risk for developing cardiovascular disease. The present study aimed to determine the age related metabolic syndrome of hemodialysis patients. The biochemical parameters and demographic information were registered. The prevalence of metabolic syndrome was significantly high in ages 50-59 and 6069 years in hemodialysis patients when compared with other age groups $(\mathrm{P}<0.05)$. There was elevated frequency of metabolic syndrome from age 50-59 and 40-49 years in male and female hemodialysis patients, respectively. The frequency of metabolic syndrome in female subjects $(65.27 \%)$ was higher than male $(47.14 \%, \mathrm{P}<0.05)$. The prevalence of metabolic syndrome was high in ages 50-59 years in males and females. There was a significant difference in hemodialysis patients with metabolic syndrome in ages 50-59 years in males and from ages 40-49, 50-59 and 60-69 years in females $(\mathrm{P}<0.05)$. Our results show that $25.71 \%, 18.57 \%$ and $2.86 \%$ males and $36.11 \%, 20.83 \%$ and $8.33 \%$ females had three, four and five criteria for metabolic syndrome, respectively. The results of this study showed that females patients were more affected than males. This may depended on the specific lifestyle alterations among females and males patients in this area.
\end{abstract}

Keywords: Gorgan, metabolic syndrome, hemodialysis, age.

\section{INTRODUCTION}

Metabolic syndrome (MS) is a complex disorder that was first described by Reaven in 1988 [1]. The characteristics of metabolic syndrome are abdominal obesity, hypertriglyceridemia, low high-density lipoprotein cholesterol levels, high blood pressure, and high fasting blood glucose levels. Age is an important factor in the incidence of metabolic syndrome in males and females, according to the National Health and Nutrition Examination Survey 1999-2000 [2].Metabolic syndrome forms a major health problem in Western countries. It may affect almost $20 \%$ of the adult population and $40 \%$ of adults over 60 years old [3]. The ageadjusted prevalence of metabolic syndrome showed an increased incidence among females $(23.5 \%)$ and males $(2.2 \%)$ in the United States during the periods 1988-1994 and 1999-2000. It has been reported that the incidence of metabolic syndrome change meaningfully among different ethnic groups [4]. Many studies have shown that metabolic syndrome is an important risk factor for some disease such as cardiovascular disease, chronic kidney disease (CKD) and death among people [5-9]. The prevalence of metabolic syndrome among renal transplant recipients has indicated to be from $38.6 \%$ to $63.4 \%[10,11]$.Data from the Third

*Address correspondence to this author at the Gorgan Faculty of Medicine, Department of Biochemistry and Biophysics, Metabolic Disorders Research Center, Gorgan Faculty of Medicine, Golestan_University of Medical Sciences, Gorgan, Golestan Province, Iran; Tel; +98(171)4421651;

Fax: +98(171) 4440225; E-mail:abdoljalal@yahoo.com
National Health and Nutrition Examination Survey (NHANES III) has shown that $23.7 \%$ US residents aged 20 years and older have metabolic syndrome [12]. Study of Gu et al. [13] showed that $15.1 \%$ of Chinese adults aged 35 to 74 years have metabolic syndrome.Young and coworkers showed that the incidence of metabolic syndrome was up to $70 \%$ in hemodialysis patients [14]. They have indicated that metabolic syndrome was more prevalent among diabetic, female, and white end-stage renal disease patients. In our area, we do not have enough information about age related metabolic syndrome among hemodialysis patients. The present study aimed to determine the age related metabolic syndrome of hemodialysis patients in Gorgan, Golestan province (South East of Caspian Sea), Iran.

\section{MATERIALS AND METHODS}

This cross sectional study was done on hemodialysis patients who were referred to 5th Azar Educational Hospital, Dialysis Center (The only Educational Dialysis Center) in Gorgan, Golestan province (South East of Caspian Sea), Iran in 2012. Hundred and fifty hemodialysis patients centered to this study. Patients were excluded from the study if they experienced prior transplantation and have recovered kidney function, stop with dialysis, have acute renal failure and deaths. At the time of this study, eight patients were excluded. Hundred and forty two hemodialysis patients remained for further study. The mean age of patients was $53.53 \pm 15.2$ years old. There were 70 males $(49.3 \%)$ and 72 females $(50.7 \%)$. An overnight fasting (after 12-h) venous blood sample was collected for determination of serum cho- 
lesterol, triglycerides, LDL-cholesterol, HDL-cholesterol and fasting blood sugar. Commercial kits were used to determine the biochemical parameters implementing spectrophotometer techniques at laboratory of 5th Azar Educational Hospital. Demographic information was registered. Systolic and diastolic blood pressure was measured in sitting position from the right hand. We have done two measurements from all hemodialysis patients. Waist circumference was measured at the point halfway between the lower border of ribs and the iliac crest in a horizontal plane. Hemodialysis patients were considered to have metabolic syndrome if they had any three or more of the following criteria, according to the ATP III (Adult Treatment Panel III) [5]:

1) Abdominal obesity: $\mathrm{WC}>102 \mathrm{~cm}$ (males) and $>88 \mathrm{~cm}$ (females).

2) Hypertriglyceridemia: serum triglycerides level $\geq 150$ $\mathrm{mg} / \mathrm{dl}$.

3) Low HDL-cholesterol: $<40 \mathrm{mg} / \mathrm{dl}$ in men and $<50 \mathrm{mg} / \mathrm{dl}$ in women.

4) High blood pressure: $\mathrm{SBP} \geq 130 \mathrm{mmHg}$ and/or DBP $\geq 85$ $\mathrm{mmHg}$ or on treatment for hypertension.

5) High fasting glucose: serum glucose level $\geq 110 \mathrm{mg} / \mathrm{dl}$ or on treatment for diabetes.

The results have shown as percentages and mean \pm SD. SPSS- 16 version software was used for the statistical analysis. The results were appraised by using Chi-square test. $\mathrm{P}<$ 0.05 was considered statistically significant.

\section{RESULTS}

A total of 142 hemodialysis patients were studied. Table 1 shows the distribution of hemodialysis patients according to gender and age. The mean age of males and females patients was $55.27 \pm 16.42$ and $51.83 \pm 13.43$ years, respectively. There were $70(49.30 \%)$ males and $72(50.70 \%)$ females. The most age distribution in males and females was in ages between 50-59 and 60-69 years. Table 2 shows hemodialysis patients with and without metabolic syndrome. The prevalence of metabolic syndrome was significantly high in range of 50-59 and 60-69 years in hemodialysis patients when compared with other age groups $(\mathrm{P}<0.05)$. Table 3 shows hemodialysis patients with and without metabolic syndrome by gender and age. There was elevated frequency of metabolic syndrome from age 50-59 and 40-49 years in male and female hemodialysis patients, respectively. The frequency of metabolic syndrome in female subjects $(65.27 \%)$ was higher than male $(47.14 \%)(\mathrm{P}<0.05)$. The prevalence of metabolic syndrome was high in ages 50-59 years in males and females when compared with other age groups. There was a significant difference in hemodialysis patients with metabolic syndrome in ages 50-59 years in males and from ages 40-49, 50-59 and 60-69 years in females when compared with other age groups. There were no significant differences in hemodialysis patients with metabolic syndrome in other age groups. Table 4 shows number of hemodialysis patients accomplishing the criteria of metabolic syndrome. Our results show that $25.71 \%, 18.57 \%$ and $2.86 \%$ of males and $36.11 \%, 20.83 \%$ and $8.33 \%$ of females

Table 1. Distribution of Hemodialysis Subjects by Gender and Age

\begin{tabular}{|c|c|c|}
\hline Females $(\mathbf{n}=\mathbf{7 2})$ & Males $(\mathbf{n}=\mathbf{7 0})$ & Age Groups in Years \\
\hline \hline $6(8.33)$ & $4(5.71)$ & $20-29 \mathrm{n}(\%)$ \\
\hline $8(11.11)$ & $7(10)$ & $30-39 \mathrm{n}(\%)$ \\
\hline $12(16.66)$ & $9(12.85)$ & $40-49 \mathrm{n}(\%)$ \\
\hline $21(29.16)$ & $18(25.71)$ & $50-59 \mathrm{n}(\%)$ \\
\hline $20(27.77)$ & $16(22.85)$ & $60-69 \mathrm{n}(\%)$ \\
\hline $5(6.94)$ & $16(22.85)$ & $70+\mathrm{n}(\%)$ \\
\hline $51.83 \pm 13.43$ & $55.27 \pm 16.42$ & Ages (years) \\
\hline
\end{tabular}

Table 2. Distribution of Hemodialysis Subjects with and without Metabolic Syndrome

\begin{tabular}{|c|c|c|}
\hline Without MS & With MS & Age Groups in Years \\
\hline \hline $10(7.04)$ & $0(0 \%)$ & $20-29 \mathrm{n}(\%)$ \\
\hline $11(7.74)$ & $4(2.81)$ & $30-39 \mathrm{n}(\%)$ \\
\hline $8(5.63)$ & $13(9.15)$ & $40-49 \mathrm{n}(\%)$ \\
\hline $8(5.63)^{*}$ & $31(21.83)$ & $50-59 \mathrm{n}(\%)$ \\
\hline $13(9.15)^{*}$ & $23(16.19)$ & $60-69 \mathrm{n}(\%)$ \\
\hline $12(8.45)$ & $9(6.33)$ & $70+\mathrm{n}(\%)$ \\
\hline $62(43.66)$ & $80(56.33)$ & Total $\mathrm{n}(\%)$ \\
\hline
\end{tabular}

MS: Metabolic Syndrome, ${ }^{*} \mathrm{P}$ value less than 0.05 was considered significant. 
Table 3. Hemodialysis Subjects with and Without Metabolic Syndrome by Gender and Age

\begin{tabular}{|c|c|c|c|c|}
\hline \multirow{2}{*}{ Age Groups in Years } & \multicolumn{2}{|c|}{ Males (n=70) } & \multicolumn{2}{|c|}{ Females (n=72) } \\
\cline { 2 - 5 } & With MS & Without MS & With MS & Without MS \\
\hline \hline $20-29 \mathrm{n}(\%)$ & $0(100)$ & $4(14.28)$ & $0(100)$ & $6(8.33)$ \\
\hline $30-39 \mathrm{n}(\%)$ & $2(2.85)$ & $5(7.14)$ & $2(2.77)$ & $2(2.33)$ \\
\hline $40-49 \mathrm{n}(\%)$ & $3(4.28)$ & $6(8.25)$ & $10(13.88)$ & $4(5.55)^{*}$ \\
\hline $50-59 \mathrm{n}(\%)$ & $14(20)$ & $4(5.71)^{*}$ & $17(23.61)$ & $5(6.94)^{*}$ \\
\hline $60-69 \mathrm{n}(\%)$ & $8(11.42)$ & $8(11.42)$ & $3(4.15)$ & $2(2.77)$ \\
\hline $70+\mathrm{n}(\%)$ & $6(8.25)$ & $10(14.28)$ & $47(65.27)$ & $25(34.73)$ \\
\hline Total n (\%) & $33(47.14)$ & $37(52.86)$ & & \\
\hline
\end{tabular}

MS: Metabolic Syndrome, *P value less than 0.05 was considered significant.

Table 4. Number of Hemodialysis Subjects Accomplishing the Criteria of Metabolic Syndrome

\begin{tabular}{|c|c|c|}
\hline Females(n=72) & Males(n=70) & Parameters \\
\hline \hline $26(36.11)$ & $18(25.71)$ & 4 criteria $\mathrm{n}(\%)$ \\
\hline $15(20.83)$ & $13(18.57)$ & 5 criteria $\mathrm{n}(\%)$ \\
\hline $6(8.33)$ & $2(2.86)$ & 5 criteria $\mathrm{n}(\%)$ \\
\hline $47(65.27)$ & $33(47.14)$ & Total criteria $\mathrm{n}(\%)$ \\
\hline
\end{tabular}

had three, four and five criteria for metabolic syndrome, respectively.

\section{DISCUSSION}

The prevalence of the metabolic syndrome is increasing a lot around the world. There are many studies with different findings on prevalence of metabolic syndrome among hemodialysis patients. Prevalence of metabolic syndrome changes as age proceeds. The present cross-sectional study showed the prevalence of the metabolic syndrome among female and male hemodialysis patients was $65.27 \%$ and $47.14 \%$, respectively. Some study showed that the prevalence of the metabolic syndrome was $15.3 \%, 23.1 \%, 28.0 \%, 26.0 \%$, and $20.5 \%$ among people aged from 30 to 39,40 to 49,50 to 59 , 60 to 69,70 to 79 and $\geq 80$ years old, respectively [15]. Hildrum et.al indicated that prevalence of the metabolic syndrome increased with age into the ninth decade of life [16]. Ford et al. reported that the prevalence of the metabolic syndrome was $16.5 \%, 40.3 \%$, and $46.4 \%$ in males, and $19.1 \%$, $33.8 \%$, and $56.0 \%$, respectively, in females among US population aged from 20 to 39,40 to 59 and $\geq 60$ years old, respectively. It has been shown that there was an association between older age subjects and a higher prevalence of metabolic syndrome [17]. Study of Park et al. showed that the prevalence of the metabolic syndrome elevates from age 20 years old through the sixty and seventy years old for males and females, respectively. Chen and colleagues [7] reported that the prevalence of metabolic syndrome in chronic kidney disease patients was $2.6 \%$ higher when compared with those without metabolic syndrome. Elsaid et al. showed that the incidence of metabolic syndrome in hemodialysis patients was $62 \%$. Prevalence of metabolic syndrome among females $(74.4 \%)$ was more common than males $(52.7 \%)$ [18]. Study of Al Saran et al. [19] showed that the prevalence of metabolic syndrome in hemodialysis patients was $62 \%$. The prevalence of metabolic syndrome was higher among females $(67 \%)$ than males $(50 \%)$ which were in agreement with the findings of Hsu, Williams and Stephan et al. [2022]. Study of Stoli et al. [23] indicated that about 30\% of hemodialysis patients having progressed metabolic syndrome which was not in agreement with our findings. In our study, the prevalence of metabolic syndrome was higher in females than males in ages $50-59$ years which is in agreement with other findings [7, 18-22]. A study showed that metabolic syndrome is diagnosed in more than $60 \%$ of dialyzed patients [24] Study of Ford et al. showed that the agespecific prevalence of MS increased from $10.7 \%$ of males and $18.0 \%$ of females aged $20-39$ years to $39.7 \%$ of males and $46.1 \%$ of females aged 60 years and older [2]. Similar results have been reported in European and Chinese populations $[13,25]$. Some studies have shown the association between metabolic syndrome and risk of chronic kidney disease $[7,26,27]$. It is reported that the metabolic syndrome was associated with a 2.60- and 1.89-fold elevated risk of chronic kidney disease in US adults [7]. Tanaka and colleagues showed that metabolic syndrome was significantly associated with chronic kidney disease among Japaneese participants aged 30-79 years in a hospital-based screening program in Okinawa [27].

\section{CONCLUSION}

The results of this study showed that hemodialysis females patients were more affected than males. This may de- 
pend on the specific lifestyle alterations among females and males patients. Determination of metabolic syndrome allows us to predict cardiovascular disease in hemodialysis patients.

\section{CONFLICT OF INTEREST}

The authors confirm that this article content has no conflicts of interest.

\section{ACKNOWLEDGEMENTS}

The authors would like to thank the colleagues at the dialysis center and laboratory of $5^{\text {th }}$ Azar Educational Hospital (Faculty of Medicine, Golestan University of Medical Science) for their cooperation in the handling of experiments.

\section{REFERENCES}

[1] Reaven, G.M. The metabolic syndrome: requiescat in pace. Clin. Chem., 2005, 51, 931-938.

[2] Ford, E.S.; Giles, W.H.; Mokdad, A.H. Increasing prevalence of the metabolic syndrome among U.S. adults. Diabetes Care, 2004, 27, 2444-2449.

[3] Scott, C.L. Diagnosis, prevention, and intervention for the metabolic syndrome. Am. J. Cardiol., 2003, 92, 35i-42i.

[4] Anand, S.S.; Yi, Q.; Gerstein, H.; Lonn, E.; Jacobs, R.; Vuksan, V.; Teo, K.; Davis, B.; Montague, P.; Yusuf, S. Relationship of metabolic syndrome and fibrinolytic dysfunction to cardiovascular disease. Circulation, 2003, 108, 420-425.

[5] [No author listed]. Executive Summary of the Third Report of the National Cholesterol Education Program (NCEP) Expert Panel on Detection, Evaluation, and Treatment of High Blood Cholesterol in Adults (Adult Treatment Panel III). JAMA, 2001, 285, 2486-2497.

[6] [No author listed]. Third Report of the National Cholesterol Education Program (NCEP) Expert Panel on Detection, Evaluation, and Treatment of High Blood Cholesterol in Adults (Adult Treatment Panel III) final report. Circulation, 2002, 106, 3143-3421.

[7] Chen, J.; Muntner, P.; Hamm, L.L.; Jones, D.W.; Batuman, V.; Fonseca, V.; Whelton, P.K.; He, J. The metabolic syndrome and chronic kidney disease in U. S. adults. Ann. Intern. Med., 2004, 140, 167-174.

[8] Isomaa, B.; Almgren, P.; Tuomi, T.; Forsén, B.; Lahti, K.; Nissén, M.; Taskinen, M.R.; Groop, L. Cardiovascular morbidity and mortality associated with the metabolic syndrome. Diabetes Care, 2001, 24, 683-689.

[9] Lakka, H.M.; Laaksonen, D.E.; Lakka, T.A.; Niskanen, L.K.; Kumpusalo, E.; Tuomilehto, J.; Salonen, J.T. The metabolic syndrome and total and cardiovascular disease mortality in middleaged men. JAMA, 2002, 288, 2709-2716.

[10] de Vries, A.P.; Bakker, S.J.; van Son, W.J.; van der Heide J.J.: Ploeg, R.J. The, H.T.; de Jong, P.E.; Gans, R.O. Metabolic syndrome is associated with impaired long-term renal allograft function; not all component criteria contribute equally. Am. J. Transplant, 2004, 4, 1675-1683.

[11] Holdaas, H.; Fellstrom, B.; Jardine, A.; Gimpelewicz, C.; Staffler, B.; Logan, J. Prevalence and consequences of metabolic syndrome in a renal transplant population. J. Am. Sec. Nephrol., 2004, 15, 572A.

[12] Ford, E.S.; Giles, W.H.; Dietz, W.H. Prevalence of the metabolic syndrome among US adults: findings from the third National Health and Nutrition Examination Survey. JAMA, 2002, 287, 356359.

[13] Gu, D.; Reynolds, K.; Wu, X.; Reynolds, R.F.; Whelton, P.K.; He, J. InterASIA Collaborative Group. InterASIA Collaborative Group. Prevalence of the metabolic syndrome and overweight among adults in China. Lancet, 2005, 365, 1398-1405.

[14] Young, D.O.; Lund, R.J.; Haynatzki, G.; Dunlay, R.W. Prevalence of the metabolic syndrome in an incident dialysis population. Hemodial Int., 2007, 11, 86-95.

[15] Sanisoglu, S.Y.; Oktenli, C.; Hasimi, A.; Yokusoglu, M.; Ugurlu, M. Prevalence of metabolic syndrome-related disorders in a large adult population in Turkey. BMC Public Health, 2006, 6, 92.

[16] Hildrum, B.; Mykletun, A.; Hole, T.; Midthjell, K.; Dahl, A.A. Age-specific prevalence of the metabolic syndrome defi Ned by the International Diabetes Federation and the National Cholesterol Education Program: the Norwegian HUNT 2 study. BMC Public Health, 2007, 7, 220.

[17] Ford, E.S.; Li, C.; Imperatore, G.; Cook, S. Age, sex.; and ethnic variations in serum insulin concentrations among US youth: findings from the National Health and Nutrition Examination Survey 1999-2002. Diabetes Care, 2006, 29, 2605-2611.

[18] Elsaid, S.A.; Hamada, M.A.; Alsaran, K.A. Obesity and metabolic syndrome in Saudi hemodialysis patients. J. Nephrol. Ren. Transplant., 2009, 2, 18-27.

[19] Al Saran, K.; Elsayed, S.; Sabry, A.; Hamada, M. Obesity and Metabolic Syndrome in hemodialysis patients: Single Center Experience. Saudi J. Kidney Dis. Transpl., 2001, 22(6), 1193-1198.

[20] Hsu, C.Y.; McCulloch, C.E.; Iribarren, C. Body mass index and risk for end stage renal disease. Ann. Intern. Med., 2006,144, 2128 .

[21] Williams, J.D.; Woods, H.F. Insulin resistance, the metabolic syndrome and renal failure - is there a special problem for patients treated with peritoneal dialysis?" Eur. Endocrine. Rev., 2006, 29, 351-366.

[22] Stephan, J. L.; Bakker, R.; Gansevoort, T.; de Zeeuw D. Metabolic syndrome: a fata morgana? Nephrol. Dial. Transplant, 2007, 22, 15- 20.

[23] Stoli, R.; Trajkovi, G.; Peri, V.; Jovanović, A.; Stolić, D.; Sovtić, S.; Subarić-Gorgieva, G. Frequency and characteristics of metabolic disorders in patients on haemodialysis. Vojnosanit Pregl., 2008, 65, 205-209.

[24] Grzegorzewska, A.E. Metabolic syndrome in dialyzed patients. Diagnosis and insulin resistance. Pol. Merkur. Lekarski., 2010, 28(164), 162-165.

[25] Hu, G.; Qiao, Q.; Tuomilehto, J.; Balkau, B.; Borch-Johnsen, K.; Pyorala, K. Prevalence of the metabolic syndrome and its relation to all-cause and cardiovascular mortality in nondiabetic European men and women. Arch. Intern. Med., 2004, 164, 1066-1076.

[26] Kurella, M.; Lo, J.C.; Chertow, G.M. Metabolic syndrome and the risk for chronic kidney disease among nondiabetic adults. $J$. Am. Soc. Nephrol., 2005, 16, 2134-2140

[27] Tanaka, H.; Shiohira, Y.; Uezu, Y.; Higa, A.; Iseki, K. Metabolic syndrome and chronic kidney disease in Okinawa, Japan. Kidney Int., 2006, 69, 369-374

This is an open access article licensed under the terms of the Creative Commons Attribution Non-Commercial License (http://creativecommons.org/licenses/by-nc/3.0/) which permits unrestricted, non-commercial use, distribution and reproduction in any medium, provided the work is properly cited. 